\title{
OPTIMALISASI PENGATURAN PERIKANAN LEMURU BERDASARKAN MEKANISME SUPPLY DAN DEMAND DI SELAT BALI
}

\author{
Yesi Dewita Sari', Sonny Koeshendrajana' dan Benny Osta Nababan² \\ ${ }^{1}$ Peneliti pada Balai Besar Riset Sosial Ekonomi Kelautan dan Perikanan \\ JI. KS. Tubun Petamburan VI, Jakarta 10260 \\ Telp. 021 53650162/Fax. 02153650159 \\ ${ }^{2}$ Tenaga Pengajar pada Institut Pertanian Bogor.
}

\begin{abstract}
ABSTRAK
Penelitian ini bertujuan untuk menentukan jumlah alat tangkap yang dioperasikan pada perikanan lemuru di Selat Bali, yang didasarkan pada mekanisme keseimbangan supply dan demand. Pendugaan parameter biologi dilakukan menggunakan model CYP, pendugaan kurva supply menggunakan model Clark dan pendugaan kurva demand menggunakan model Salvatore. Hasil analisis menunjukkan bahwa keseimbangan supply dan demand terjadi pada tingkat harga Rp 5.889 dengan jumlah produksi 10.149 ton per tahun. Sementara itu, berdasarkan hasil survei diperoleh data bahwa harga ikan lemuru berkisar antara Rp 1.500 - 2.000 dengan rata-rata jumlah produksi (tahun 1990-2007) 30.254 ton dengan rata-rata upaya penangkapan 16.934 trip per tahun. Pada kondisi Maximum Sustainable Yield diperoleh maksimum jumlah tangkapan adalah 21.418 ton per tahun dengan jumlah upaya penangkapan 8.023 trip per tahun. Jumlah upaya penangkapan ini setara dengan 81 unit purse seine dengan asumsi setiap unit purse seine memiliki 99 trip per tahun. Mengacu kepada jumlah produksi pada kondisi MSY, maka dengan jumlah produksi 10.149 ton per tahun pada kondisi keseimbangan supply dan demand, hanya 38 unit purse seine yang diperlukan di Selat Bali. Kebijakan pembatasan jumlah upaya penangkapan di lokasi tersebut diharapkan mampu memulihkan sumberdaya ikan lemuru, dan dalam jangka panjang eksploitasi dapat dilakukan secara optimal.
\end{abstract}

Kata Kunci : Bioekonomi, Supply, Demand, Perikanan Lemuru, Selat Bali, Alat Tangkap

\section{Abstract : Optimalization of Governing 'Lemuru' Fishery Based on the Supply and Demand Mechanism in the Bali Strait. By: Yesi Dewita Sari, Sonny Koeshendrajana and Benny Osta Nababan.}

This research aimed to know amount of fishing effort for capturing lemuru in the Bali Strait based on supply demand equilibrium. Biology parameters were estimated by using CYP model, supply curve was estimated using Clark model and demand curve wos estimated using Salvatore model. Results show that supply demand equilibrium is reached at Rp 5,889 of price and 10,149 MT per year of harvest. Based on survey, price of lemuru was around Rp 1,500 - 2,000 with average of harvest (1990-2007) was 30,254 MT per year. At maximum sustainable yield (MSY), maximum harvest were 21,418 MT per year and fishing effort 8,023 trip per year. Fishing effort at MSY were 81 unit purse seine assuming that one unit purse seine operated 99 trips peryear. Based on fishing effort and harvested fish at the MSY, with 10,149 ton per years at the equilibrium point of supply and demand of that particular fish, it required 38 units of purse seine in the Bali Strait. Limiting number of fishing effort in the Bali Strait is to be expected by which enabling to recover lemuru required in the long-run optimal exploitation rate of the lemuru.

Keywords: Bioeconomic, Supply, Demand, Lemuru, Bali Strait, 


\section{PENDAHULUAN}

Perikanan adalah salah satu sektor yang diandalkan untuk pembangunan masa depan Indonesia, karena dapat memberikan dampak ekonomi kepada sebagian penduduk Indonesia. Produk perikanan adalah bahan makanan penting bagi masyarakat pada umumnya, sehingga sektor perikanan menjadi salah satu sumber pendapatan negara dan menjadi sumber mata pencaharian di sebagian besar masyarakat di kawasan pantai terutama nelayan.

Dalam mempertahankan ketersediaan dan keberlanjutan sumberdaya perikanan tangkap perlu dilakukan pendekatan kehatihatian dalam melakukan eksploitasi. Oleh karena itu dalam eksploitasi sumberdaya perikanan tangkap diperlukan dugaan potensi sumberdaya perikanan yang dapat memberikan gambaran mengenai tingkat dan batas maksimal dalam pemanfaatan sumberdaya perikanan di suatu perairan, sehingga pembangunan perikanan dapat direncanakan sedemikian rupa dan sumberdaya perikanan dapat dimanfaatkan secara berkelanjutan.

Ikan lemuru merupakan ciri dari perairan Selat Bali karena ikan lemuru yang terdapat di Selat Bali berbeda dengan ikan lemuru yang dihasilkan wilayah lain. Pengelolaan pemanfaatan ikan lemuru dilakukan dengan menerbitkan Surat Keputusan Bersama (SKB) antara Pemerintah Propinsi Jawa Timur dan Pemerintah Propinsi Bali. Berdasarkan SKB 238/ 1992, 674/1992 tanggal 14 Nopember 1992, jumlah purse seine yang diperbolehkan adalah 273 unit, dengan kuota 190 unit Jawa Timur dan 83 unit Bali. Menurut beberapa hasil penelitian, eksploitasi lemuru di Selat Bali telah mengalami over fishing. Salah satu cara yang dapat dilakukan untuk mengatasinya yaitu dengan mengurangi jumlah alat tangkap yang dioperasikan. Tulisan ini memaparkan berapa seharusnya jumlah alat tangkap yang dapat dioperasikan untuk menangkap ikan lemuru di Selat Bali jika dilihat dari keseimbangan supply dan demand.

\section{METODOLOGI}

\section{Lokasi dan Waktu Penelitian}

Penelitian dilakukan di Selat Bali yang masuk dalam wilayah administrasi Propinsi Jawa Timur dan Propinsi Bali. Wilayah Propinsi Jawa Timur yaitu kabupaten Banyuwangi khususnya Kecamatan Muncar. Wilayah Propinsi Bali yaitu Kabupaten Jembrana, khususnya Kecamatan Pengambengan. Penelitian dilakukan pada bulan April-Oktober tahun 2007.

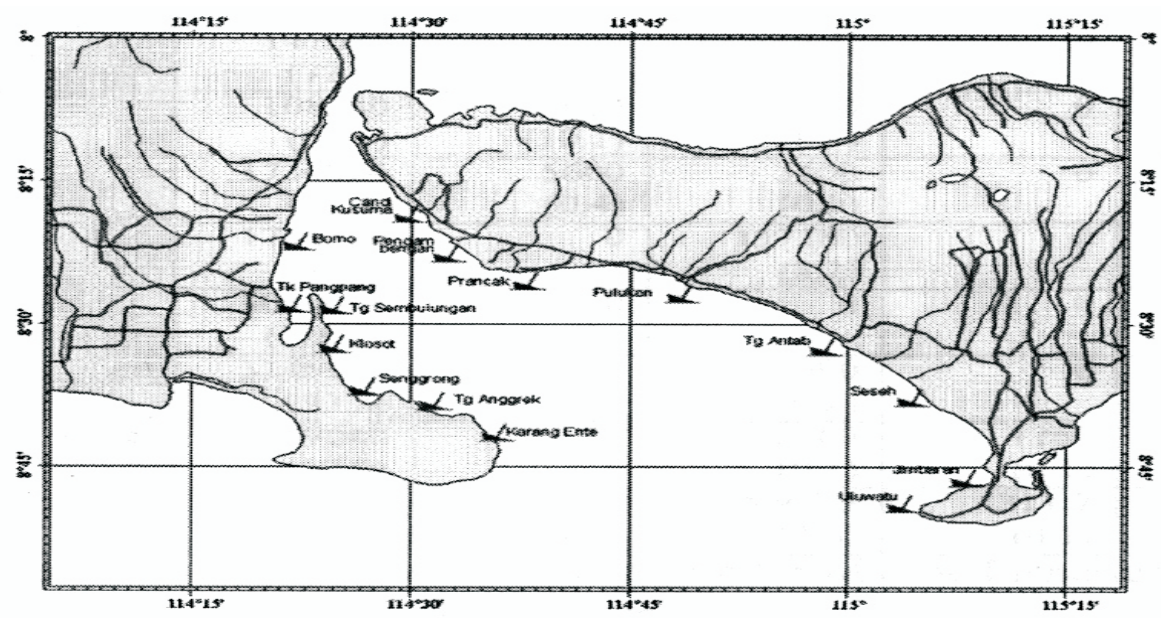

Gambar 1. Peta Selat Bali.(Sumber: ftp://ftp.fao.org/docrep/fao/field/006/ad656e/AD656E02.pdf). Figure 1. Map Bali Strait (Source: ftp://ftp.fao.org/docrep/fao/field/006/ad656e/AD656E02.pdf). 
Jenis, Sumber dan Cara Pengumpulan Data

Data yang dikumpulkan adalah data primer dan data sekunder. Data primer adalah data yang langsung diperoleh dari pengamatan atau pengukuran langsung dari objek penelitian. Dalam penelitian ini, pengumpulan data primer dilakukan dengan cara wawancara langsung dengan para nelayan dan para pejabat pemerintah pengelola sumberdaya perikanan dan juga pejabat instansi-instansi terkait. Pengamatan dilakukan terhadap tingkat kesejahteraan pelaku perikanan dibandingkan dengan masyarakat lain yang bekerja di luar bidang perikanan. Data primer yang dikumpulkan antara lain: jenis armada dan alat tangkap yang digunakan, rata-rata trip, jumlah dan jenis hasil tangkapan nelayan per trip dalam kurun waktu tertentu, biaya-biaya dalam melakukan penangkapan, pendapatan dari hasil tangkapan, serta informasi lainnya yang dirinci dalam kuesioner.

Data sekunder diperoleh dari Badan Pusat Statistik, Dinas Perikanan dan Kelautan Propinsi Jawa Timur, Dinas Kelautan dan Perikanan Bali, Dinas Kelautan dan Perikanan Kabupaten Banyuwangi, Dinas Pertanian, Kehutanan dan Kelautan Kabupaten Jembrana, Pelabuhan Perikanan Pantai Pengambengan, Tempat Pendaratan peraturan yang mengatur pengelolaan sumberdaya perikanan di pesisir, dan data lainnya yang relevan terhadap tujuan penelitian.

Teknik pengambilan sampel yang digunakan adalah purposive sampling yaitu nelayan yang menggunakan alat tangkap untuk menangkap ikan lemuru.

\section{Metode Analisis Data}

Metode analisis data terdiri dari metode untuk pendugaan parameter-parameter yang digunakan dan metode untuk pendugaan kurva supply dan demand sumberdaya ikan lemuru di Selat Bali. Parameter yang digunakan dalam penelitian ini dapat dibedakan yaitu parameter biologi dan parameter ekonomi. Parameter biologi yang diduga adalah parameter pertumbuhan intrinsik ikan ( $r$ ), daya dukung lingkungan (K) dan kemampuan alat tangkap dalam melakukan penangkapan ikan (q). Sedangkan parameter ekonomi yaitu harga input dalam melakukan penangkapan, harga output ikan lemuru dan discount rate.

Parameter biologi diduga dengan menggunakan model surplus produksi yang dikemukakan Clark, Yoshimoto and Pooley (1992) lebih dikenal dengan metode CYP. Persamaan CYP dalam bentuk matematis dapat ditulis sebagai berikut:

$$
\ln \left(U_{t+1}\right)=\frac{2 r}{(2+r)} \ln (q K)+\frac{(2-r)}{2+r} \ln \left(U_{t}\right)-\frac{q}{(2+r)}\left(E_{t}+E_{t+1}\right)
$$

Perikanan Pengambengan, Pangkalan Pendaratan Ikan Muncar, Tempat Pendaratan Ikan Muncar serta instansi-instansi terkait lainnya yang memiliki data sesuai dengan kebutuhan penelitian ini. Data sekunder antara lain berupa time series jenis dan jumlah hasil tangkapan, jumlah armada penangkapan, jumlah dan jenis alat tangkap, jumlah nelayan, tingkat harga, tingkat suku bunga, indeks harga konsumen, tingkat inflasi, dimana:

$$
U_{t}=\frac{C}{E}
$$

Dengan meregresikan hasil tangkap per unit input (effort) yang dilambangkan dengan $U$ pada periode $t+1$ dan dengan $U$ pada periode $t$, serta penjumlahan input pada periode $\mathrm{t}$ dan $\mathrm{t}+1$, akan diperoleh koefisien $\mathrm{r}$, $\mathrm{q}$ dan $\mathrm{K}$ secara terpisah. Selanjutnya setelah 
disederhanakan persamaan diatas dapat diestimasikan dengan OLS melalui:

$$
\operatorname{Ln}\left(U_{t+1}\right)=C_{1}+C_{2} \ln \left(U_{t}\right)+C_{3}\left(E_{t}+E_{t+1}\right) . .
$$

Sehingga nilai parameter $r$, q dan $\mathrm{K}$ dapat diperoleh melalui persamaan berikut:

$$
\left.\begin{array}{l}
\mathrm{r}=\frac{2(1-\mathrm{C} 2)}{(1+\mathrm{C} 2)} \\
\mathrm{q}=-\mathrm{C}_{3}(2+\mathrm{r}) \\
\mathrm{K}=\frac{e^{C_{1}(2+r) /(2 r)}}{q}
\end{array}\right\}
$$

Parameter harga dan biaya dalam penelitian ini diasumsikan konstan. Pendugaan harga ikan lemuru diperoleh dari data sekunder. Harga yang digunakan adalah rata-rata harga riil yaitu harga nominal setiap tahunnya dikalikan dengan indeks harga konsumen dibagi dengan 100. Komponen biaya yang digunakan terdiri dari biaya investasi, biaya variabel dan biaya tetap.

Perhitungan discount rate untuk estraksi sumberdaya perikanan dengan mengacu kepada metode yang dikemukakan Clark (1990). Perhitungan discount rate dalam (Clark, 1990) diperoleh dari persamaan berikut:

$$
\delta_{\text {riil }}=\ln \left(1+i_{\text {riil }}\right)
$$

Keterangan:

$$
\begin{aligned}
& \delta_{\text {riil }}=\text { discount rate riil } \\
& i_{\text {riil }}=\text { interest rate riil }
\end{aligned}
$$

Model penawaran ini menggunakan model dinamis ekonomi perikanan digambarkan melalui fungsi logistik yang telah dikembangkan pada analisis statik. Jika diasumsikan bahwa permintaan terhadap ikan elastis sempurna, dengan harga output konstan dan total biaya linier terhadap effort maka keuntungan dalam suatu periode t pada suatu industri maka menurut Fauzi (2004) dapat ditulis sebagai berikut:

$$
\begin{aligned}
\pi & =p h_{t}-c E \\
& =p h_{t}-c \frac{h_{t}}{q x_{t}}
\end{aligned}
$$

Jika diasumsikan bahwa stok dalam keadaan keseimbangan dengan menggunakan Hamiltonian didapatkan (Clark, 1990):

$\frac{\partial F}{\partial x}+\frac{\partial \pi / \partial x}{\partial \pi / \partial h}=\delta$

Persamaan di sebelah kiri merupakan manfaat marjinal yang diperoleh dari biomassa dan rente ekonomi, sementara yang di sebelah kanan adalah biaya marjinal dari kapital yang digunakan. Dengan demikian persamaan (6 dapat ditulis menjadi (Clark, 1990):

$\frac{1}{\delta} \frac{\partial \pi}{\partial x}=\frac{\partial \pi}{\partial h}$

Baik persamaan (6) maupun persamaan (7) akan menghasilkan solusi eksplisit jika diketahui fungsi pertumbuhan biomas ikan serta fungsi produksi (panen). Khusus untuk model pertumbuhan Schaefer dengan fungsi produksi Cobb-Douglas, maka dihasilkan (Clark, 1990):

$$
\begin{aligned}
& \pi(x, h)=p h-c \frac{h}{q x}=\left(p-\frac{c}{q x}\right) h \\
& \frac{\partial F}{\partial x}=r\left(1-\frac{2 x}{K}\right) \\
& \frac{\partial \pi}{\partial x}=\frac{c h}{q x^{2}} \\
& \frac{\partial \pi}{\partial h}=\left(p-\frac{c}{q x}\right)
\end{aligned}
$$


Dengan mensubstitusikan hasil dari persamaan (8) ke persamaan (6), maka akan dihasilkan (Clark, 1990):

$h^{*}=\frac{1}{c} x(p q x-x)(\delta-r(1-2 x / K))$

Kemudian, harus diingat bahwa Golden rule juga mengharuskan persamaan $F(x)=h$ dipenuhi, sehingga dengan mensubstitusikan persamaan (10):

$h=\operatorname{rx}(1 /) x \quad K$

ke persamaan (9) akan diperoleh nilai optimal biomas sebesar (Clark, 1990):

$x^{*}=\frac{K}{4}\left[\left(\frac{c}{p q K}+1-\frac{\delta}{r}\right)+\sqrt{\left(\frac{c}{p q K}+1-\frac{\delta}{r}\right)^{2}+\frac{8 c \delta}{p q K r}}\right]$

Nilai upaya yang optimal dapat diperoleh dengan mensubstitusi $x^{*}$ dan $h^{*}$ ke dalam persamaan (12):

$E^{*}=h^{*} / q x^{*}$

Dengan mengetahui nilai biomass optimal (MEY) pada persamaan (13):

$x^{*}=\frac{h}{q \cdot E}$

dan mensubsitusi ke persamaan (10) maka diperoleh persamaan suplai (Clark, 1990):
$D M=h=a-b \cdot p$

Keterangan :

$\begin{array}{ll}\mathrm{DM} & =\text { Demand } \\ \mathrm{h} & =\text { Produksi/Production } \\ \mathrm{a} & =\text { Intercept(maksimum permintaan) } \\ \mathrm{b} & =\text { Slope (kemiringan kurva } \\ & \text { permintaan) } \\ \mathrm{p} & =\text { Harga/Price }\end{array}$

\section{HASIL DAN PEMBAHASAN}

\section{Pendugaan Parameter}

Ikan lemuru merupakan ikan target yang ditangkap di Selat Bali karena lebih dari $70 \%$ komposisi hasil tangkapan ikan di Selat Bali terdiri dari ikan lemuru. Ikan lemuru ditangkap oleh nelayan dalam berbagai ukuran, yaitu kecil (sempenit dan protolan) dan ukuran besar (lemuru dan lemuru kucing). Jenis alat tangkap yang dominan digunakan oleh nelayan Jawa Timur (berbasis di Muncar, Kabupaten Banyuwangi) dan Bali (berbasis di Pengambengan, Kabupaten Jembrana) adalah jaring pukat cincin dengan nama lokal "slerek" (purse seine). Penangkapan ikan dengan menggunakan purse seine dilakukan pada malam hari dengan pola "memburu ikan" (gadangan). Pada umumnya operasi penangkapan ikan dilakukan dengan metode "two-boat system" yaitu menggunakan 2 buah kapal. Penangkapan dilakukan setiap hari (one day fishing) kecuali pada saat bulan penuh (terang bulan).

$$
h_{s}=\frac{r K}{4}\left[\frac{c}{p q K}+1-\frac{\delta}{r}+\sqrt{\left(\frac{c}{p q K}+1-\frac{\delta}{r}\right)^{2}}+\frac{8 c \delta}{p q K r}\right]\left(1+\left[-\frac{1}{4} \frac{c}{p q K}-\frac{1}{4}+\frac{1}{4} \frac{\delta}{r}-\frac{1}{4} \sqrt{\left(\frac{c}{p q K}+1-\frac{\delta}{r}\right)^{2}}+\frac{8 c \delta}{p q K r}\right]\right)
$$

Menurut Salvatore (1992), fungsi permintaan: $Q_{d}=a-b \cdot p$ dan fungsi penawaran: $Q_{s}=c+d \cdot p$ dengan asumsi semua produksi terjual sesuai dengan permintaan maka: $Q_{d}=Q_{s}$ dalam suplai sumberdaya ikan lemuru yang diketahui sebagai h sehingga: $Q_{s}=h$ Oleh karena itu, dalam Oostenbrugge (2003) diacu dalam Nababan (2006) fungsi permintaan (DM) menjadi:

\section{Pendugaan Parameter Biologi}

Dalam menduga parameter biologi terhadap pemanfaatan sumberdaya ikan lemuru di Selat Bali diperlukan adanya data jumlah produksi dan upaya penangkapan ikan lemuru tersebut. Upaya penangkapan yang digunakan dalam penelitian ini adalah jumlah trip. Jumlah produksi dan trip ikan lemuru di Selat Bali disajikan pada Tabel 1. 
Pendugaan parameter biologi ikan lemuru di Selat Bali dilakukan dengan menggunakan metode yang dikemukakan oleh Clark, Yoshimoto and Pooley, 1992 (CYP) diacu dalam Fauzi, 2004. Metode tersebut menggunakan OLS (Ordinary Least Square) atau regresi linier dengan menggunakan data logaritma CPUE pada waktu $t+1$ sebagai peubah tidak bebas dan logaritma CPUE pada waktu t dan jumlah effort pada waktu t dan $\mathrm{t}+1$

Tabel 1. Produksi dan Upaya Penangkapan Ikan Lemuru di Selat Bali Tahun 1980-2007. Table 1. Production and Fishing Effort of the Lemuru Fish in Bali Strait, 1980-2007.

\begin{tabular}{ccc}
\hline Tahun/Year & Produksi (ton)/ Production (ton) & $\begin{array}{c}\text { Upaya Penangkapan (trip)/ } \\
\text { Fishing Effort (trip) }\end{array}$ \\
\hline 1980 & $17.281,20$ & 14.003 \\
1981 & $20.768,00$ & 21.242 \\
1982 & $37.957,10$ & 18.393 \\
1983 & $47.154,40$ & 15.221 \\
1984 & $31.847,80$ & 13.646 \\
1985 & $14.653,10$ & 6.751 \\
1986 & $31.882,53$ & 29.797 \\
1987 & $11.395,35$ & 9.909 \\
1988 & $34.859,50$ & 10.075 \\
1989 & $32.600,30$ & 12.302 \\
1990 & $53.254,72$ & 14.752 \\
1991 & $44.215,08$ & 16.196 \\
1992 & $33.180,69$ & 19.363 \\
1993 & $46.030,61$ & 16.381 \\
1994 & $44.516,16$ & 14.268 \\
1995 & $37.698,80$ & 19.030 \\
1996 & $38.660,85$ & 19.955 \\
1997 & $46.243,92$ & 13.443 \\
1998 & $31.213,52$ & 30.013 \\
1999 & $11.864,90$ & 10.055 \\
2000 & $11.408,00$ & 9.200 \\
2001 & $17.941,44$ & 13.592 \\
2002 & $29.837,81$ & 30.447 \\
2003 & $29.332,87$ & 30.555 \\
2004 & $29.585,97$ & 30.501 \\
2005 & $12.582,80$ & 14.389 \\
2006 & $37.269,59$ & 15.433 \\
2007 & $39.751,82$ & 17.246 \\
\hline Rata-rata/Avarage & $31.249,60$ & 17.363 \\
& & \\
\hline & &
\end{tabular}

Sumber: Tinungki (2005); Tempat Pelelangan Ikan Muncar dan Tempat Pelelangan Ikan Pengambengan (Tahun 1982-2008).

Source: Tinungki (2005); Fishing Port of Muncar and Pangambengan (1982-2008). 
$\left(\ln \left(U_{t+1}\right)\right)$ sebagai peubah bebas tidak bebas dan logaritma CPUE pada waktu $t$ $\left(\ln \left(U_{t}\right)\right)$ dan jumlah effort pada waktu tan $\mathrm{t}+1\left(E_{t}+E_{t+1}\right)$ sebagai peubah bebas.

Output OLS memberikan nilai intersept $(\mathrm{a}=1,1854)$, koefisien untuk variabel $\ln \left(U_{t}\right)$ $(\mathrm{b}=0,2923)$ dan koefisien untuk variabel $\left(E_{t}+E_{t+1}\right)$ (c=-0,00002) atau $\ln \left(U_{t+1}\right)=1,1854+0,2923 \ln \left(U_{t}\right)$ $-0,00002\left(E_{t}+E_{t+1}\right)$. Dari nilai tersebut dapat diduga nilai tingkat pertumbuhan intrinsik ( $r$ ), koefisien kemampuan tangkap (q) dan daya dukung lingkungan perairan (K). Koefisien tersebut disajikan pada Tabel 2.

\section{Pendugaan Parameter Ekonomi}

Parameter ekonomi yang digunakan dalam penelitian ini adalah harga jual ikan lemuru, biaya penangkapan dan discount rate. Harga yang digunakan dalam penelitian ini adalah rata-rata harga riil. Penggunaan harga riil dimaksudkan agar harga tersebut dapat diperbandingkan setiap tahunnya. Harga diperoleh dari data Dinas Perikanan dan Kelautan Propinsi Jawa Timur dan Biro Pusat Statistik (BPS). Dengan diketahuinya rata-rata harga setiap tahun tersebut kemudian dikalikan dengan indeks harga konsumen, kemudian dibagi 100. Indeks harga konsumen yang digunakan adalah indeks harga konsumen dengan tahun dasar tahun 2002. Rata-rata harga riil yang diperoleh dalam penelitian ini adalah Rp.1.671,16 per kg, merupakan harga rata-rata dari tahun 19902007. Harga tersebut digunakan untuk analisis selanjutnya dalam penelitian ini. Harga riil ikan lemuru setiap tahunnya disajikan pada Tabel 3 .

Variabel biaya yang digunakan dalam penelitian ini adalah rata-rata biaya penangkapan setiap trip. Dalam hal ini, data yang digunakan adalah biaya penangkapan alat tangkap purse seine yaitu sebesar Rp 4.321.024 per trip. Interest rate yang digunakan dalam menghitung discount rate adalah real interest rate. Real interest rate

Tabel 2. Parameter Biologi Sumberdaya Ikan Lemuru di Selat Bali, Tahun 2008.

Table 2. Biological Parameters of the Lemuru Fish in the Bali Strait, 2008.

\begin{tabular}{cccc}
\hline No & $\begin{array}{c}\text { Koefisien/ } \\
\text { Coefisien }\end{array}$ & \multicolumn{1}{c}{$\begin{array}{c}\text { Definisi / } \\
\text { Definition }\end{array}$} & $\begin{array}{c}\text { Nilai/ } \\
\text { Value }\end{array}$ \\
\hline 1 & $\mathrm{r}$ & $\begin{array}{l}\text { Tingkat pertumbuhan intrinsik/ } \\
\text { Intrinsic growth rate } \\
\text { Kemampuan tangkap/ } \\
\text { Catchability coefisien } \\
\text { Daya dukung perairan / } \\
\text { Carrying capacity }\end{array}$ & 1,0952000 \\
3 & $\mathrm{q}$ & $\mathrm{K}$ & $\mathbf{7 8 . 2 2 2 , 3 1 0 0 0 0 0}$ \\
\hline
\end{tabular}

Tabel 3. Harga Ikan Lemuru, Indeks Harga Konsumen (IHK), Harga Riil Ikan Lemuru di Selat Bali, Tahun 1990 - 2007.

Table 3. Price of Lemuru, Consumer Price Index and Real Price of Lemuru in the Bali Strait, 1990 - 2007.

\begin{tabular}{cccc}
\hline Tahun/Year & $\begin{array}{c}\text { Harga Ikan Lemuru }(\mathrm{Rp} / \mathrm{kg}) / \\
\text { Price of Lemuru }(\mathrm{kg} / \mathrm{Rp})\end{array}$ & IHK/CPI & $\begin{array}{c}\text { Harga Riil }(\mathrm{Rp} / \mathrm{kg}) / \\
\text { Real Price }(\mathrm{kg} / \mathrm{Rp})\end{array}$ \\
\hline 1990 & 217,09 & 246,90 & 535,99 \\
1991 & 124,67 & 253,02 & 315,45 \\
1992 & 137,78 & 126,27 & 173,97 \\
1993 & 199,76 & 156,85 & 313,32 \\
1994 & 237,97 & 176,67 & 420,41 \\
\hline
\end{tabular}


Lanjutan dari tabel 3/ Continue table 3

\begin{tabular}{cccc}
\hline Tahun/Year & $\begin{array}{c}\text { Harga Ikan Lemuru (Rp/kg)/ } \\
\text { Price of Lemuru (kg/Rp) }\end{array}$ & IHK/CPI & $\begin{array}{c}\text { Harga Riil (Rp/kg)/ } \\
\text { Real Price (kg/Rp) }\end{array}$ \\
\hline 1995 & 239,27 & 204,39 & 489,05 \\
1996 & 305,73 & 242,23 & 740,57 \\
1997 & 168,43 & 250,99 & 422,74 \\
1998 & 597,96 & 165,58 & 990,11 \\
1999 & $1.750,00$ & 255,68 & $4.474,40$ \\
2000 & $2.447,78$ & 218,69 & $5.353,06$ \\
2001 & $1.944,11$ & 275,85 & $5.362,82$ \\
2002 & $1.063,13$ & 100,00 & $1.063,13$ \\
2003 & $1.257,00$ & 102,54 & $1.288,93$ \\
2004 & $1.498,00$ & 108,10 & $1.619,34$ \\
2005 & $1.599,00$ & 125,09 & $2.000,19$ \\
2006 & $1.485,00$ & 141,48 & $2.100,98$ \\
2007 & $1.605,00$ & 150,55 & $2.416,33$ \\
\hline Rata-rata/Average & 937,65 & & $1.671,16$
\end{tabular}

Sumber: Data Diolah Tahun 2008/Source: Data Processed, 2008.

diperoleh dari nominal interest rate dikurangi dengan tingkat inflasi. Perhitungan discount rate yang dilakukan dalam penelitian ini adalah rata-rata interest rate dari tahun 1994 sampai dengan tahun 2004. Perhitungan interest rate real pada tahun 1998 sama dengan interest rate nominal, karena tingkat inflasi pada tahun tersebut sangat tinggi sekali, sehingga tidak dapat dipergunakan. Interest rate nominal, inflasi dan social discount rate disajikan pada Tabel 4. Social discount rate diperoleh dari LN(1+interest rate real). Nilai social interest rate yang digunakan untuk analisis selanjutnya adalah rata-rata social discount rate selama 11 tahun tersebut yaitu $8,61 \%$.

\section{Analisis Supply dan Demand}

Kurva penawaran sumberdaya ikan lemuru di Selat Bali dapat digambarkan dengan menggunakan persamaan 14 dengan nilai parameter-parameter yang telah diketahui. kurva penawaran disajikan pada gambar 2a. kurva penawaran perikanan memiliki kemiringan yang positif sampai dengan jumlah produksi pada titik Maximum Sustainable Yield (MSY), setelah itu kurva akan berbalik ke belakang. Kondisi ini menunjukkan jika jumlah produksi lebih rendah dari MSY maka peningkatan harga akan meningkatkan jumlah produksi atau jumlah penangkapan. Tetapi jika produksi telah melebihi jumlah MSY maka peningkatan harga akan menyebabkan jumlah produksi yang semakin kecil karena stok sumberdaya yang akan semakin berkurang.

Kurva permintaan yang terlihat seperti pada Gambar 2b diperoleh dengan mengacu pada model permintaan yang dikemukakan oleh Salvatore (1992). Kurva permintaann tersebut diperoleh dari hasil regresi jumlah hasil tangkapan aktual dengan harga riil. Pada penelitian ini meregresikan produksi aktual dan harga riil tahun 1990 sampai dengan tahun 2007. Input data yang digunakan untuk menduga kurva permintaan disajikan pada Tabel 5. 


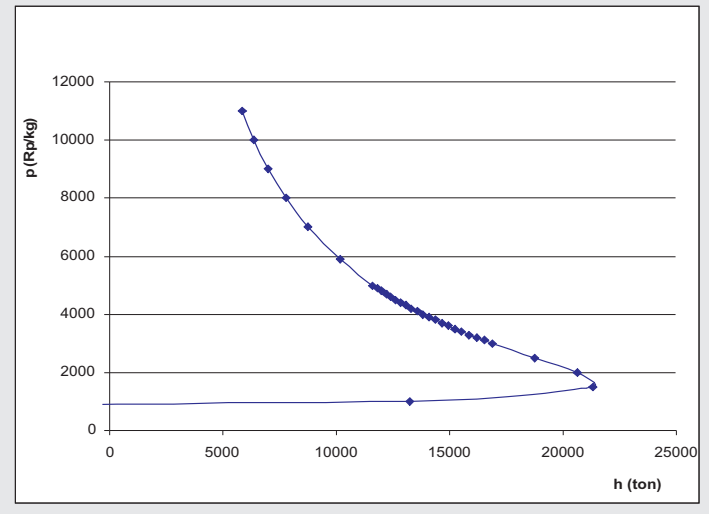

2a. Kurva Penawaran/Supply Curve

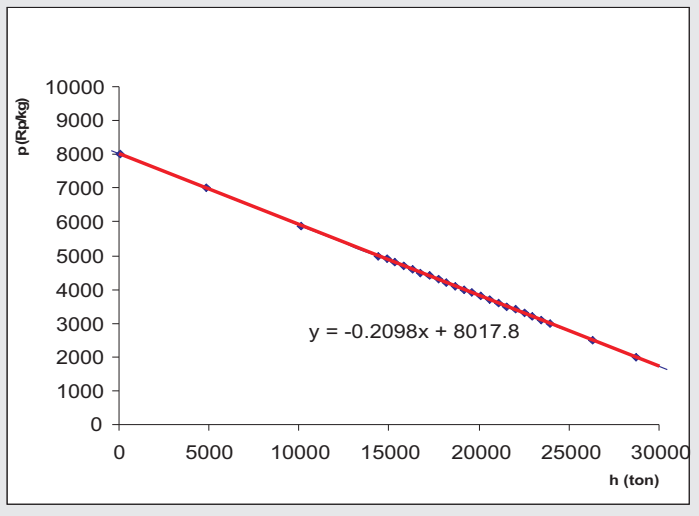

2b. Kurva Permintaan/Demand Curve

Gambar 2. Kurva Penawaran dan Permintaan Sumberdaya Ikan Lemuru di Selat Bali.

Figure 2. Supply and Demand Curve of Lemuru in Bali Strait.

Tabel 4. Nominal Interest Rate, Inflasi dan Social Discount Rate.

Table 4. Nominal Interest Rate, Inflation and Social Discount Rate.

\begin{tabular}{cccc}
\hline $\begin{array}{c}\text { Tahun / } \\
\text { Year }\end{array}$ & $\begin{array}{c}\text { Interest Rate Nominal / } \\
\text { Nominal Interest Rate (\%) }\end{array}$ & $\begin{array}{c}\text { Inflasi/ } \\
\text { Inflation (\%) }\end{array}$ & $\begin{array}{c}\text { Social Discount Rate } \\
\text { LN (1+l) Riil }\end{array}$ \\
\hline 1994 & 14,26 & 9,24 & 4,90 \\
1995 & 14,50 & 8,64 & 5,69 \\
1996 & 15,08 & 6,47 & 8,26 \\
1997 & 15,48 & 11,05 & 4,34 \\
1998 & 18,92 & 77,63 & 17,33 \\
1999 & 20,93 & 2,01 & 17,33 \\
2000 & 16,32 & 9,35 & 6,74 \\
2001 & 16,44 & 12,55 & 3,82 \\
2002 & 17,47 & 10,03 & 7,18 \\
2003 & 16,87 & 5,06 & 11,16 \\
2004 & 14,65 & 6,40 & 7,93 \\
\hline & Rata-rata/Average & & $\mathbf{8 . 6 1}$ \\
\hline
\end{tabular}

Tabel 5. Produksi Aktual dan Harga Riil Ikan Lemuru di Selat Bali Tahun 1990-2004. Table 5. Actual Production and Real Price of Lemuru in the Bali Strait, 1990-2004.

\begin{tabular}{crc}
\hline $\begin{array}{c}\text { Tahun/ } \\
\text { Year }\end{array}$ & $\begin{array}{r}\text { Produksi Aktual (ton)/ } \\
\text { Actual Production (ton) }\end{array}$ & $\begin{array}{c}\text { Harga Riil }(\mathrm{Rp} / \mathrm{kg}) / \\
\text { Real Price }(\mathrm{kg} / \mathrm{Rp})\end{array}$ \\
\hline 1990 & $53.254,72$ & 535,99 \\
1991 & $44.215,08$ & 315,45 \\
1992 & $33.180,69$ & 173,97 \\
\hline
\end{tabular}


Lanjutan dari tabel 5/ Continue table 5

\begin{tabular}{ccc}
\hline $\begin{array}{c}\text { Tahun/ } \\
\text { Year }\end{array}$ & $\begin{array}{c}\text { Produksi Aktual (ton)/ } \\
\text { Actual Production (ton) }\end{array}$ & $\begin{array}{c}\text { Harga Riil }(\mathrm{Rp} / \mathrm{kg}) / \\
\text { Real Price }(\mathrm{kg} / \mathrm{Rp})\end{array}$ \\
\hline 1993 & $46.030,61$ & 313,32 \\
1994 & $44.516,16$ & 420,41 \\
1995 & $17.698,80$ & 489,05 \\
1996 & $8.660,85$ & 740,57 \\
1997 & $46.243,92$ & 422,74 \\
1998 & $31.213,52$ & 990,11 \\
1999 & $11.864,90$ & $4.474,40$ \\
2000 & $11.408,00$ & $5.353,06$ \\
2001 & $17.941,44$ & $5.362,82$ \\
2002 & $29.837,81$ & $1.063,13$ \\
2003 & $29.332,87$ & $1.288,93$ \\
2004 & $29.582,97$ & $1.619,34$ \\
2005 & $12.582,80$ & $2.000,19$ \\
2006 & $37.269,59$ & $2.100,98$ \\
2007 & $39.751,82$ & $2.416,33$
\end{tabular}

Sumber: Data Diolah Tahun 2008/Source: Data Processed, 2008.

Dari hasil regresi terhadap harga ikan sebagai peubah bebas dan produksi aktual sebagai peubah tidak bebas diperoleh nilai intersep 38.221,23 dan nilai koefisien harga ikan -4,7670. Dengan diketahuinya nilai intersep dan koefisien ini maka besarnya permintaan dapat diperoleh berdasarkan besarnya tingkat harga yang terjadi. Besarnya tingkat harga yang terjadi diregresikan dengan demand, maka kurva permintaan dapat diperoleh. kurva permintaann ini menunjukkan kemiringan/slope yang negatif yaitu sebesar 0,2098 dengan intersep 8017,8 . Permintaan terhadap ikan lemuru di Selat Bali memiliki sifat yang sama dengan permintaan terhadap barang lainnya yaitu semakin banyak jumlah produksi maka harga akan semakin rendah. Pada pengelolaan sumberdaya perikanan, nelayan tidak dapat menentukan harga ikan, karena harga ikan ditentukan oleh pasar. Berdasarkan kurva permintaan yang diduga, jika produksi ikan lemuru di Selat Bali hanya 1000 ton per tahun maka konsumen atau pembeli akan membayar ikan lemuru seharga Rp. 7.800 per kg.
Keseimbangan supply dan demand terjadi pada harga Rp.5.889 dan produksi 10.149 ton per tahun (Gambar 2). Dari hasil survei diketahui bahwa harga ikan yang dipasarkan di Selat Bali (Muncar dan Pengambengan) berkisar antara Rp 1.500 2.000 tergantung dari ukuran dan kondisi/mutu ikan yang didaratkan. Sedangkan dari data sekunder yang dikumpulkan diperoleh ratarata jumlah produksi/hasil tangkapan setiap tahunnya dari tahun 1990-2007 adalah 30.254,81 ton per tahun. Dengan mensubstitusikan rata-rata jumlah produksi dari data sekunder tersebut ke kurva permintaan yang telah diduga di atas diperoleh harga ikan lemuru sebesar Rp. 1.670 per kg.

Berdasarkan hasil analisis yang dilakukan dengan menggunakan parameterparameter yang telah dipaparkan di atas diperoleh Maximum Sustainable Yield (MSY) sumberdaya ikan lemuru di Selat Bali adalah 21.418 ton dengan jumlah upaya penangkapan (trip) sebesar 8.023 trip per tahun. Dengan demikian dapat dikatakan bahwa rata-rata jumlah produksi aktual telah 
lebih tinggi dari MSY dengan harga yang lebih rendah dari tingkat keseimbangan supply dan demand. Jumlah produksi yang lebih tinggi dari MSY tidak dapat digambarkan dalam kurva penawaran.

Berdasarkan rata-rata jumlah trip beberapa kapal yang melakukan penangkapan ikan di Selat Bali diketahui bahwa 1 unit kapal purse seine melakukan penangkapan sebanyak 9 kali dalam 1 bulan, maka dalam 1 tahun terdapat 99 trip dengan asumsi penangkapan dilakukan dalam 11 bulan. Jika penangkapan dilakukan pada kondisi MSY maka alat tangkap purse seine hanya diperlukan sebanyak 81 unit. Pada kondisi MSY setiap unit purse seine menghasilkan jumlah tangkapan sebesar 264,27 ton per tahun.

Dengan asumsi setiap unit purse seine melakukan eksploitasi sebesar 264,27 ton per tahun, maka untuk memperoleh jumlah produksi pada kondisi keseimbangan supply dan demand (10.149 ton/tahun) hanya diperlukan purse seine sebanyak 38 unit. Pencapaian kondisi keseimbangan supply dan demand tidak akan mungkin terjadi alamiah. Oleh karena itu diperlukan adanya intervensi pemerintah. Hasil analisis keseimbangan supply dan demand ini diperoleh berdasarkan data yang tersedia, seperti data jumlah produksi, jumlah trip penangkapan, perkembangan harga dari tahun 1990 sampai dengan tahun 2007. Dari beberapa hasil penelitian yang dilakukan oleh Universitas Diponegoro dan Universitas Brawijaya mengatakan bahwa tingkat eksploitasi ikan lemuru di Selat Bali telah mengalami over fishing. Agar kondisi perikanan lemuru ini dapat pulih kembali pada kondisi sustainable, maka dalam keseimbangan supply dan demand hanya 38 unit purse seine yang layak untuk dioperasikan.

Pencapaian kondisi keseimbangan ini sangat sulit untuk dicapai, mengingat banyaknya masyarakat yang menggantungkan hidupnya pada sumberdaya ikan lemuru tersebut, seperti nelayan baik nelayan pemilik maupun nelayan buruh, pedagang, perusahaan pengalengan dan tepung ikan beserta seluruh karyawan perusahaan tersebut. Di lain pihak, pengelolaan ikan lemuru tersebut sudah seharusnya dilakukan pada kondisi lestari, karena jika pemanfaatan tetap dilakukan pada kondisi aktual saat ini maka sumberdaya ikan lemuru tersebut akan semakin berkurang dan dalam jangka waktu dekat dapat saja punah. Oleh karena itu, sangat diperlukan adanya campur tangan atau intervensi pemerintah dalam pengaturan pengelolaannya.

Pembatasan jumlah upaya penangkapan sudah seharusnya dilakukan, dalam beberapa tahun terakhir pengurangan jumlah upaya penangkapan dalam hal ini trip telah dilakukan oleh nelayan. Dari data hasil pendaratan ikan di TPI Muncar dan Pengambengan menunjukkan bahwa rata-rata jumlah trip masing-masing kapal yang beroperasi dalam selang waktu periode terang bulan hanya 9 trip, padahal sebenarnya nelayan dapat melakukan penangkapan lebih kurang 20 trip per periodenya. Hal ini disebabkan juga oleh semakin tingginya biaya penangkapan yang ditanggung oleh nelayan. Nelayan hanya melakukan penangkapan pada kondisi yang memungkinkan untuk pengembalian biaya operasional, jika dalam perhitungan/dugaan nelayan tersebut tidak dapat mengembalikan biaya penangkapan maka penangkapan tidak dilakukan.

\section{IV.KESIMPULAN DAN IMPLIKASI KEBIJAKAN}

\section{Kesimpulan}

Ikan lemuru di Selat Bali merupakan sumberdaya ikan yang sangat spesifik, karena hanya terdapat di Selat Bali. Oleh karena itu diperlukan suatu penanganan yang sangat hati-hati agar ikan tersebut dapat terjaga kelestariannya. Berdasarkan SKB tahun 1992, jumlah alat tangkap purse seine yang boleh dioperasikan di Selat Bali adalah 273 unit, jumlah produksi ikan lemuru pada tahun 2007 
adalah 39,75 ton dengan harga berselang antara Rp.1.500-2.000 per kg. Sedangkan melalui mekanisme atau keseimbangan supply dan demand diperoleh tingkat harga ikan lemuru seharusnya Rp.5.889 dengan jumlah produksi 10.149 ton per tahun. Untuk memproduksi jumlah kuantitas tersebut hanya 38 unit purse seine yang boleh dioperasikan.

\section{Implikasi Kebijakan}

Untuk mencapai kondisi keseimbangan tersebut sangat diperlukan adanya intervensi pemerintah, baik pemerintah pusat dan juga pemerintah daerah dalam mengatur pengelolaan pengoperasian alat tangkap di Selat Bali. Salah satu cara yang paling cepat dapat dilakukan adalah dengan melakukan pengaturan jadwal penangkapan masingmasing armada yang ada. Setiap armada yang ada hanya boleh melakukan penangkapan sesuai jadwal yang ditentukan, sehingga jumlah trip penangkapan tidak melebihi jumlah trip dari 38 unit armada purse seine.

\section{DAFTAR PUSTAKA}

Anonimous. 2007. Jumlah Hasil Tangkapan ikan. Tempat Pelelangan Ikan Muncar.

Anonimous. 2007. Jumlah Hasil Tangkapan Ikan. Tempat Pelelangan Ikan Pengambengan.

Clark, C W. 1990. Mathematical
Bioeconomics. The Optimal Management of Renewable Resources. 2nd ed. WileyInterscience. New York.

Fauzi, A. 2004. Ekonomi Sumber Daya Alam dan Lingkungan. PT. Gramedia Pustaka Utama. Jakarta.

Nababan, B.O. 2006. Analisa Dampak Perdagangan Ikan Karang Hidup Konsumsi (Life Reef Fish Food) Terhadap Sumberdaya Perikanan (Studi Kasus di Provinsi Sulawesi Selatan). Tesis. Sekolah Pascasarjana IPB. Tidak dipublikasikan.

Salvatore, D 1992. Microeconomic Theory Third Edition. By Mc Graw-Hill. Inc

Tinungki, G. M. 2005. Evaluasi Model Produksi Surplus Dalam Menduga Hasil Tangkapan Maksimum Lestari Untuk Menunjang Kebijakan Pengelolaan Perikanan Lemuru Di Selat Bali. Disertasi. Tidak dipublikasikan. Sekolah Pascasarjana - Institut Pertanian Bogor. 